\title{
Identification of novel target genes of nerve growth factor (NGF) in human mastocytoma cell line (HMC-1 (V560G c-Kit)) by transcriptome analysis
}

Priyanka Dutta ${ }^{1 \dagger}$, Alexandra Koch ${ }^{1 \dagger}$, Bjoern Breyer ${ }^{1}$, Heike Schneider ${ }^{1}$, Oliver Dittrich-Breiholz ${ }^{1}$, Michael Kracht ${ }^{2}$ and Teruko Tamura ${ }^{1 *}$

\begin{abstract}
Background: Nerve growth factor (NGF) is a potent growth factor that plays a key role in neuronal cell differentiation and may also play a role in hematopoietic differentiation. It has been shown that NGF induced synergistic action for the colony formation of CD34 positive hematopoietic progenitor cells treated with macrophage-colony stimulating factor (M-CSF or CSF-1), or stem cell factor (SCF). However, the exact role of NGF in hematopoietic system is unclear. It is also not clear whether NGGF médiated signals in hematopoietic cells are identical to those in neuronal cells.
\end{abstract}

Results: To study the signal transduction pathways induced by NGF treatment in hematopoietic cells, we utilized the mastocytoma cell line HMC-1(V560G c-Kit) which expresses the NGF receptor, tropomyosin-receptor-kinase (Trk)A, as well as the constitutively activated SCF receptor, V560G c-Kit, which can be inhibited completely by treatment with the potent tyrosine kinase inhibitor imatinib mesylate (imatinib). NGF rescues HMC-1(V560G c-Kit) cells from imatinib mediated cell death and promotes proliferation. To examine the NGF mediated proliferation and survival in these cells, we compared the NGF mediated upregulated genes (30 and 120 min after stimulation) to the downregulated genes by imatinib treatment (downregulation of c-Kit activity for $4 \mathrm{~h}$ ) by transcriptome analysis. The following conclusions can be drawn from the microarray data: Firstly, gene expression profiling reveals $50 \%$ overlap of genes induced by NGF-TrkA with genes expressed downstream of V560G c-Kit. Secondly, NGF treatment does not enhance expression of genes involved in immune related functions that were down regulated by imatinib treatment. Thirdly, more than 55\% of common upregulated genes are involved in cell proliferation and survival. Fourthly, we found Kruppel-like factor (KLF) 2 and Smad family member 7 (SMAD7) as the NGF mediated novel downstream genes in hematopoietic cells. Finally, the downregulation of KLF2 gene enhanced imatinib induced apoptosis.

Conclusion: NGF does not induce genes which are involved in immune related functions, but induces proliferation and survival signals in HMC-1(V560G c-Kit) cells. Furthermore, the current data provide novel candidate genes, KLF2 and SMAD7 which are induced by NGF/TrkA activation in hematopoietic cells. Since the depletion of KLF2 causes enhanced apoptosis of HMC-1(V560G c-Kit), KLF2 may play a role in the NGF mediated survival signal.

\section{Background}

Nerve growth factor (NGF) is a member of the family of neurotrophins and is essential for the survival and differentiation of neurons in central and peripheral nerve systems [1]. The binding of NGF to its high affinity receptor, tropomyosin-receptor-kinase(Trk)A, causes

\footnotetext{
* Correspondence: tamura.teruko@MH-Hannover.de

† Contributed equally

${ }^{1}$ Institut fuer Biochemie, OE4310, Medizinische Hochschule Hannover,

Carl-Neuberg-Str. 1, D-30623 Hannover, Germany

Full list of author information is available at the end of the article
}

activation of the receptor associated tyrosine kinase and participates in the control of mitogenic, survival or differentiation pathways. It has been suggested that NGF and its receptor may also be involved in hematopoietic cell development $[2,3]$. In those studies NGF induced synergistic action for the colony formation of CD34 positive hematopoietic progenitor cells treated with the macrophage colony stimulating factor (M-CSF, or CSF-1) [3], or stem cell factor (SCF) [2]. However, the exact role of TrkA in hematopoietic cell differentiation remains unclear.

\section{C) Biomed Central}


The receptor for SCF, c-Kit tyrosine kinase plays a key role in hematopoietic stem cell and mast cell survival, mitogenesis, proliferation, differentiation, adhesion, homing, migration, and functional activation. Despite diversity in the mechanisms of their activation by growth factor ligands [4], most receptor tyrosine kinases induce signals through the same pathways to typically enhance proliferation and prolong viability. These pathways include activation of the Ras/Raf/Erk, activation of signal transducers and activators of transcription (STATs), and phosphatidylinositol 3 kinase (PI3K). Indeed, c-Kit activation induces all of these pathways, while activated TrkA induces Ras/ Raf/Erk, and PI3K pathways but does not cause tyrosine phosphorylation of endogenous STATs [5,6], suggesting that SCF and NGF not only induce common signal pathways, but also induce unique signal pathways. However, the differences between a set of genes which are upregulated by NGF and those upregulated by SCF in hematopoietic cells has not yet been studied.

The rat pheochromocytoma cell line, PC12, is one of the most thoroughly established systems to study the NGF mediated signal transduction pathway followed by neuronal differentiation. Various studies have investigated gene expression profiles in NGF-treated PC12 cells [7-14], however whether these upregulated genes are similar to genes in the hematopoietic system is not clear. Interestingly, leukemogenic mutant TrkA [5] does not induce tumor formation, but induces the differentiation of PC12 cells (Koch and Breyer, unpublished data), suggesting that NGF/TrkA signaling is different in neuronal and hematopoietic cells. We have previously shown that NGF-TrkA signaling partially rescues TrkA expressing Bcr-Abl transformed chronic myelogenous leukemia (CML) cells, such as K562, and Meg-01, from cell death induced by a potent inhibitor of Bcr-Abl tyrosine kinase, imatinib mesylate (imatinib). However, the effects of NGF on imatinib treated CML cells are modest. In the presence of NGF, the number of living K562 cells treated with imatinib increased by only 1.5 -fold within 4 days and Meg-01 cells did not grow, but just survived for a longer period [15]. A dramatic effect of NGF treatment was observed in oncogenic c-Kit (V560G c-Kit) transformed human mastocytoma cells (HMC-1 (V560G c-Kit))[16] which are also induced to undergo apoptosis by treatment with imatinib. HMC-1 (V560G c-Kit) cells continue to grow nearly normally in the presence of both imatinib and NGF [15].

In this paper, using HMC-1 (V560G c-Kit) cells we compared NGF and SCF signaling in the same cell system. HMC-1 [16] expresses the activated SCF receptor, V560G and/or D816V c-Kit $[17,18]$ and TrkA $[19,20]$. The kinase activity of V560G c-Kit can be inhibited completely by treatment with imatinib $[21,22]$ and cells died within 3 days. NGF rescues HMC-1 (V560G c-Kit) cells from imatinib mediated cell death and promotes proliferation [15], indicating that NGF can take over mitogenic signaling in these cells. Therefore, we compared the NGF mediated upregulated genes ( 30 and 120 min after stimulation) to the downregulated genes by imatinib treatment (downregulation of c-Kit for $4 \mathrm{~h}$ ) by transcriptome analysis. We found Kruppel-like factor (KLF) 2 and Smad family member 7 (SMAD7) as the NGF mediated novel down stream genes in hematopoietic cells and KLF2 may be involved in NGF mediated survival of imatinib treated cells.

\section{Results}

NGF rescues HMC-1 (V560G c-Kit) cells from imatinib mediated cell death and promotes proliferation

To assess the biological effects of NGF on HMC-1(V560G c-Kit) cells in the absence of c-Kit-mediated signal, we treated the cells with $5 \mu \mathrm{M}$ imatinib in the presence or absence of $100 \mathrm{ng} / \mathrm{ml} \mathrm{NGF}$. Viable cells were counted 1, 2, and 3 days after treatment using trypan blue cell exclusion assay. In agreement with previous data [15], more than 95\% cell death was observed within $48 \mathrm{~h}$ of treatment with imatinib alone. In sharp contrast, HMC-1(V560G c-Kit) cells treated with imatinib in the presence of NGF continued to proliferate even after $72 \mathrm{~h}$ at a rate almost similar to untreated controls (Figure 1). In fact, NGF could support long-term survival (over 1 year) of these cells in the presence of imatinib (Koch and Dutta, unpublished data). In agreement with these data NGF treatment has been shown to induce mitogenic signals in CD34 positive hematopoietic progenitor cells [2]. Interestingly, it has been reported that the NGF stimulation induces the activation

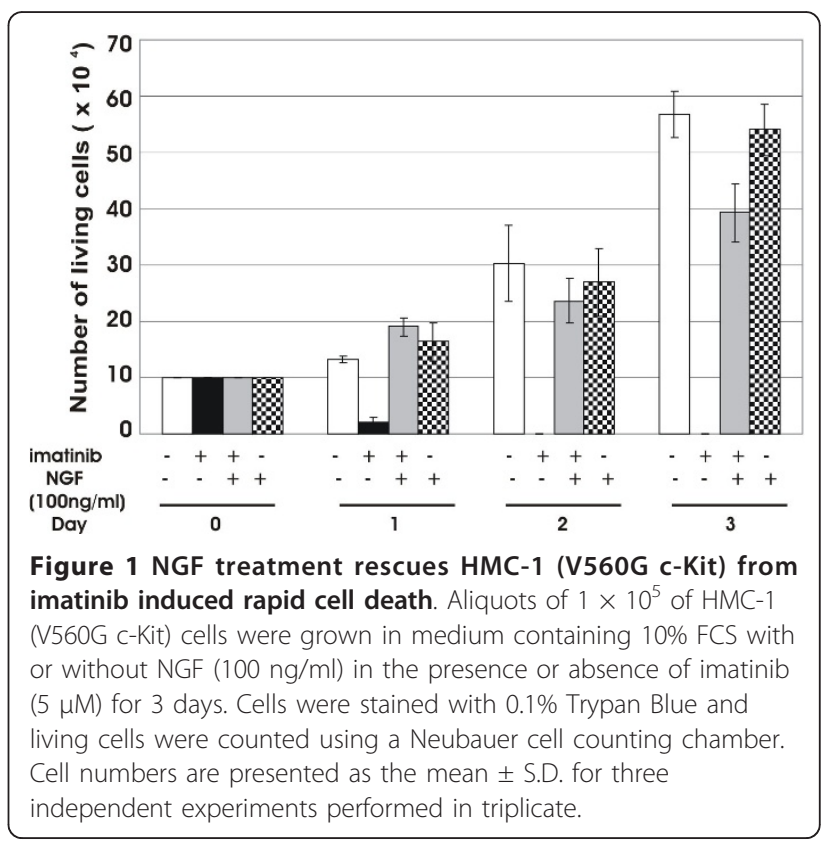


of Erk1/2 and PI3K, but does not induce tyrosine phosphorylation of STATs in PC12 cells [6], in promyeloid cell line 32D [5] or in HMC-1 cells (Koch and Dutta, unpublished data). On the other hand, STAT5 activation is required for the maintenance of mast cells [23], suggesting that NGF may induce unknown signals for the maintenance of HMC-1(V560G c-Kit) cells without STATs signaling. We next analyzed the gene profile induced by NGF treatment of HMC-1(V560G c-Kit) cells. To understand how NGF-TrkA activation counteracts the effect of c-Kit inhibition and promotes survival in HMC-1(V560G c-Kit) cells we performed gene expression profiling using a high density microarray technique employing the "Whole Human Genome Microarray" (G4112F, ID 014850, Agilent Technologies) that contains 45,015 probes. First, we determined the genes which were regulated as a result of c-Kit inhibition by comparing untreated HMC-1(V560G c-Kit) cells in serum free medium with cells after addition of $5 \mu \mathrm{M}$ imatinib for $4 \mathrm{~h}$. Second, we studied changes in gene expression caused by the addition of NGF $(100 \mathrm{ng} / \mathrm{ml})$ for $30 \mathrm{~min}$ (immediate early genes) and $2 \mathrm{~h}$ (delayed early genes) to the imatinib treated cells. Based on the filtering criteria mentioned in the methods section, 524 genes of known identities were downregulated and 328 genes were upregulated by treatment with imatinib, with expression ratios ranging from 2 to 45 -fold and 2 to 10 -fold, respectively. Twenty one genes of known identities were found induced after $30 \mathrm{~min}$ and 121 genes after $2 \mathrm{~h}$ of NGF stimulation following $4 \mathrm{~h}$ of imatinib treatment, with fold induction values ranging from 2 to 94- and 2 to 30-fold, respectively. Furthermore, NGF treatment repressed one gene after $30 \mathrm{~min}$ and seven genes after $2 \mathrm{~h}$ in imatinib treated cells.

NGF induced immediate and delayed early genes in imatinib treated HMC-1(V560G c-Kit) cells including several known NGF responsive immediate early genes such as the early growth response (EGR) family EGR1, 2 and 4, c-FOS, and JUNB being upregulated after $30 \mathrm{~min}$ of NGF treatment, followed by induction of delayed early genes such as NGFI-A binding protein 2 (NAB2), hairy and enhancer of split, (Drosophila) (HES1), Kruppel-like factor (KLF) 10, and activating transcription factors 3 (ATF3) after $2 \mathrm{~h}$.

Prominently, EGR1 (or NGF1-A), first discovered as a NGF responsive gene in PC12 cells, was induced more than 90-fold within 30 min of TrkA activation providing an initial validation for our array [7]. To gain insight into the potential mechanism by which NGF can overcome imatinib induced apoptosis we focused our further investigation on the comparison of genes that were downregulated by imatinib and up-regulated by NGF treatment for $2 \mathrm{~h}$. To derive a biological meaning from the individual lists of V560G c-Kit and NGF-TrkA- modulated genes, we uploaded these lists to Ingenuity Pathways Analysis (IPA, Ingenuity Systems, Mountain View, CA) application for biological function and pathway analysis. Out of a total of 524 genes modulated by imatinib treatment 510 genes mapped to the IPA knowledge database with 428 genes for functions/pathways analysis. Out of 117 NGF induced genes accepted by the IPA knowledge database (Table 1), 106 mapped for functions/pathways analysis. A comparison of the two gene lists revealed a common set of 58 genes out of 117 NGF upregulated genes (Table 1) that were also downmodulated by imatinib (Figure 2). This suggests that NGF-TrkA signaling regulates many genes the expression of which are also regulated by V560G c-Kit in HMC-1 cells.

\section{NGF-TrkA activation does not enhance expression of genes involved in immune related functions that were downregulated by imatinib treatment}

Since the expression of 452 genes out of 510 genes which were downregulated by imatinib treatment for $4 \mathrm{~h}$ was not restored by the stimulation with NGF for $2 \mathrm{~h}$ (Figure 2), we next analyzed the two datasets using PANTHER (Protein ANalysis THrough Evolutionary Relationships) protein class analysis which measures the significance of certain functional categories among these targets by their enrichment relative to the total numbers in their respective categories. As shown in Table 2, immune response component genes such as cytokines and cytokine receptors genes were significantly downregulated ( $\mathrm{p}=2.45 \mathrm{E}-06$ and $6.65 \mathrm{E}-04$, respectively) by imatinib treatment. In contrast, NGF-TrkA does not activate receptor genes significantly (Table 2 , NS). In addition, NGF-TrkA activated cytokine genes $(\mathrm{p}=3.33 \mathrm{E}-03)$ but drastically fewer genes than c-Kit mediated gene modulation (Table 2). These data suggest that NGF can take over the proliferation signal but not immune related function induced by c-Kit.

\section{More than $67 \%$ of NGF-TrkA upregulated genes are involved in cell survival and proliferation}

We next analyzed genes which are upregulated by NGFTrkA signaling by IPA analysis. Significantly, over $67 \%$ of upregulated genes are involved in survival and proliferation (Table 3). Although the immediate-early response genes, such as EGR4, c-FOS, or FOSB are also downstream of c-Kit signaling, these genes are not constitutively expressing. Therefore, several c-Kit inducible genes were not downregulated by imatinib treatment. To confirm the micro array data, we performed quantitative reverse-transcriptase polymerase chain reaction (qRT$\overline{\mathrm{PCR}}$ ) to examine the relative expression level of c-FOS, JUNB, EGR1, and c-MYC. HMC-1(V560G c-Kit) cells 
Table 1 List of gene set regulated by NGF in HMC-1 (V560G c-Kit) cells

\begin{tabular}{|c|c|c|c|}
\hline Symbol & $\begin{array}{c}\text { Gene } \\
\text { accession ID }\end{array}$ & Description & $\begin{array}{l}\text { Fold } \\
\text { change }\end{array}$ \\
\hline \multicolumn{4}{|c|}{ CYTOKINES } \\
\hline CLCF1 & NM_013246 & cardiotrophin-like cytokine factor 1 & 2.6 \\
\hline FASLG & NM_000639 & Fas ligand (TNF superfamily, member 6) & 3.0 \\
\hline IL1B & NM_000576 & interleukin 1, beta & 2.2 \\
\hline LIF & NM_002309 & leukemia inhibitory factor (cholinergic differentiation factor) & 2.4 \\
\hline LTB & NM_002341 & lymphotoxin beta (TNF superfamily, member 3) & 2.2 \\
\hline \multicolumn{4}{|c|}{ GROWTH FACTOR } \\
\hline GDF15 & NM_004864 & growth differentiation factor 15 & 3.2 \\
\hline \multicolumn{4}{|c|}{ ENZYMES } \\
\hline ARL5B & NM_178815 & ADP-ribosylation factor-like $5 \mathrm{~B}$ & 3.1 \\
\hline B3GALNT2 & NM_152490 & beta-1,3-N-acetylgalactosaminyltransferase 2 & 2.8 \\
\hline CYCS & NM_018947 & cytochrome c, somatic & 2.6 \\
\hline GALNT4 & NM_003774 & UDP-N-acetyl-alpha-D-galactosamine:polypeptide N-acetylgalactosaminyltransferase 4 (GalNAc-T4) & 3.2 \\
\hline GEM & NM_005261 & GTP binding protein overexpressed in skeletal muscle & 2.9 \\
\hline LFNG & NM_001040167 & LFNG O-fucosylpeptide 3-beta-N-acetylglucosaminyltransferase & 2.5 \\
\hline PAICS & NM_006452 & phosphoribosylaminoimidazole carboxylase, phosphoribosylaminoimidazole succinocarboxamide synthetase & 2.9 \\
\hline RRAD & NM_004165 & Ras-related associated with diabetes & 2.5 \\
\hline TEP1 & NM_007110 & telomerase-associated protein 1 & 3.8 \\
\hline UBE2E1 & NM_152653 & ubiquitin-conjugating enzyme E2E 1 (UBC4/5 homolog, yeast) & 4.2 \\
\hline \multicolumn{4}{|c|}{ KINASES } \\
\hline AATK & AK131529 & $\begin{array}{c}\text { cDNA FLJ16758 fis, clone BRACE3038687, moderately similar to Homo sapiens apoptosis-associated tyrosine } \\
\text { kinase (AATK) }\end{array}$ & 2.5 \\
\hline PANK2 & AL713654 & Homo sapiens mRNA; cDNA DKFZp547J0513 (from clone DKFZp547J0513). & 2.2 \\
\hline PLK3 & NM_004073 & polo-like kinase 3 (Drosophila) & 5.1 \\
\hline PRKAR2A & NM_004157 & protein kinase, cAMP-dependent, regulatory, type II, alpha & 3.4 \\
\hline SGK1 & NM_005627 & serum/glucocorticoid regulated kinase & 2.3 \\
\hline TRIB1 & NM_025195 & tribbles homolog 1 (Drosophila) & 2.8 \\
\hline \multicolumn{4}{|c|}{ LIGAND DEPENDENT NUCLEAR RECEPTOR } \\
\hline NR4A1 & NM_002135 & nuclear receptor subfamily 4, group A, member 1 & 4.7 \\
\hline NR4A2 & NM_006186 & nuclear receptor subfamily 4, group A, member 2 & 2.8 \\
\hline NR4A3 & NM_006981 & nuclear receptor subfamily 4, group A, member 3 & 2.6 \\
\hline \multicolumn{4}{|c|}{ G-PROTEIN COUPLED RECEPTORS } \\
\hline CXCR4 & NM_001008540 & chemokine (C-X-C motif) receptor 4 (CXCR4), transcript variant 1 & 2.0 \\
\hline $\mathrm{HRH} 1$ & NM_000861 & histamine receptor $\mathrm{H} 1$ & 2.1 \\
\hline \multicolumn{4}{|c|}{ PEPTIDASE } \\
\hline CTSZ & NM_001336 & cathepsin Z & 3.0 \\
\hline \multicolumn{4}{|c|}{ TRANSCRIPTON REGULATOR } \\
\hline ACTN2 & NM_001103 & actinin, alpha 2 & 2.5 \\
\hline ARNTL2 & NM_020183 & aryl hydrocarbon receptor nuclear translocator-like 2 & 2.2 \\
\hline ATF3 & NM_004024 & Homo sapiens activating transcription factor 3 (ATF3), transcript variant 2 & 2.9 \\
\hline AXUD1 & NM_033027 & AXIN1 up-regulated 1 (AXUD1) & 2.5 \\
\hline EGR1 & NM_001964 & early growth response 1 & 29.6 \\
\hline EGR2 & NM_000399 & early growth response 2 & 13.6 \\
\hline EGR3 & NM_004430 & early growth response 3 & 22.8 \\
\hline EGR4 & NM_001965 & early growth response 4 & 5.2 \\
\hline ETV5 & NM_004454 & ets variant 5 & 3.2 \\
\hline FOS & NM_005252 & FBJ murine osteosarcoma viral oncogene homolog & 3.5 \\
\hline FOSB & NM_006732 & Homo sapiens FBJ murine osteosarcoma viral oncogene homolog B (FOSB) & 3.7 \\
\hline FOSL1 & NM_005438 & FOS-like antigen 1 & 4.7 \\
\hline FOSL2 & NM_005253 & FOS-like antigen 2 & 2.5 \\
\hline HES1 & NM_005524 & hairy and enhancer of split 1, (Drosophila) & 3.4 \\
\hline
\end{tabular}


Table 1 List of gene set regulated by NGF in HMC-1 (V560G c-Kit) cells (Continued)

\begin{tabular}{|c|c|c|c|}
\hline HOXB8 & NM_024016 & homeobox B8 & 14.1 \\
\hline JUNB & NM_002229 & jun B proto-oncogene & 2.1 \\
\hline KLF10 & NM_005655 & Kruppel-like factor 10 (KLF10), transcript variant 1 & 7.5 \\
\hline KLF2 & NM_016270 & Kruppel-like factor 2 (lung) & 2.9 \\
\hline MAFF & NM_012323 & v-maf musculoaponeurotic fibrosarcoma oncogene homolog $F$ (avian) (MAFF), transcript variant 1 & 2.6 \\
\hline MYC & NM_002467 & v-myc myelocytomatosis viral oncogene homolog (avian) & 4.1 \\
\hline NAB2 & NM_005967 & NGFI-A binding protein 2 (EGR1 binding protein 2) & 2.2 \\
\hline $\mathrm{NOC} 2 \mathrm{~L}$ & NM_015658 & nucleolar complex associated 2 homolog (S. cerevisiae) & 2.6 \\
\hline PBX2 & NM_002586 & pre-B-cell leukemia homeobox 2 & 2.7 \\
\hline POLR3E & AB040885 & mRNA for KIAA1452 protein, partial cds. & 4.0 \\
\hline RYBP & NM_012234 & RING1 and $Y Y 1$ binding protein & 2.3 \\
\hline SF1 & NM_004630 & splicing factor 1 & 6.4 \\
\hline SKIL & NM_005414 & SKI-like (SKIL) & 3.1 \\
\hline SMAD7 & NM_005904 & SMAD family member 7 & 2.2 \\
\hline ST18 & NM_014682 & suppression of tumorigenicity 18 (breast carcinoma) (zinc finger protein) & 2.0 \\
\hline ZFP36 & NM_003407 & zinc finger protein 36, C3H type, homolog (mouse) & 2.3 \\
\hline ZFP36L1 & NM_004928 & zinc finger protein $36, \mathrm{C} 3 \mathrm{H}$ type-like 1 & 2.6 \\
\hline \multicolumn{4}{|c|}{ TRANSPORTERS } \\
\hline AP1S1 & NM_057089 & adaptor-related protein complex 1, sigma 1 subunit (AP1S1), transcript variant 2 & 2.3 \\
\hline APOL6 & NM_030641 & apolipoprotein L, 6 & 3.9 \\
\hline GGA1 & NM_001001560 & golgi-associated, gamma adaptin ear containing, ARF binding protein 1 & 3.1 \\
\hline MCL1 & NM_021960 & myeloid cell leukemia sequence 1 (BCL2-related) & 2.3 \\
\hline SLC2A14 & BC060766 & $\begin{array}{l}\text { solute carrier family } 2 \text { (facilitated glucose transporter), member 14, mRNA (cDNA clone MGC:71510 } \\
\qquad \text { IMAGE:5297510), complete cds. [BC060766] }\end{array}$ & 2.9 \\
\hline SLC2A3 & NM_006931 & solute carrier family 2 (facilitated glucose transporter), member 3 & 2.5 \\
\hline STX1A & NM_004603 & syntaxin 1A (brain) (STX1A) & 2.5 \\
\hline TMC6 & NM_152453 & transmembrane and coiled-coil domains 5 (TMCO5) & 3.3 \\
\hline \multicolumn{4}{|c|}{ PHOSPHATASES } \\
\hline DUSP4 & NM_001394 & dual specificity phosphatase 4 & 2.7 \\
\hline DUSP5 & NM_004419 & dual specificity phosphatase 5 & 2.1 \\
\hline DUSP6 & NM_001946 & dual specificity phosphatase 6 & 19.9 \\
\hline EYA4 & NM_004100 & eyes absent homolog 4 (Drosophila) & 2.1 \\
\hline \multicolumn{4}{|c|}{ OTHERS } \\
\hline ADM & NM_001124 & adrenomedullin & 2.4 \\
\hline CASC5 & NM_170589 & cancer susceptibility candidate 5 (CASC5), transcript variant 1 & 3.3 \\
\hline CCDC71 & NM_022903 & coiled-coil domain containing 71 & 3.1 \\
\hline CCND1 & NM_053056 & cyclin D1 & 8.3 \\
\hline CDKN1A & NM_000389 & cyclin-dependent kinase inhibitor 1A (p21, Cip1) & 2.5 \\
\hline CLN8 & NM_018941 & ceroid-lipofuscinosis, neuronal 8 (epilepsy, progressive with mental retardation) & 2.2 \\
\hline PSCD4 & NM_013385 & pleckstrin homology, Sec7 and coiled-coil domains 4 (PSCD4), & 3.4 \\
\hline DDIT4 & NM_019058 & Homo sapiens DNA-damage-inducible transcript 4 (DDIT4), & 2.4 \\
\hline FAM40B & NM_020704 & family with sequence similarity 40, member B (FAM40B) & 4.4 \\
\hline FBXL17 & BC018548 & F-box and leucine-rich repeat protein 17, mRNA (cDNA clone IMAGE:4215262), partial cds. [BC018548] & 5.1 \\
\hline FST & NM_013409 & follistatin & 2.2 \\
\hline GNL3L & NM_019067 & guanine nucleotide binding protein-like 3 (nucleolar)-like & 2.3 \\
\hline GOLGA1 & NM_002077 & golgin $\mathrm{A} 1$ & 3.7 \\
\hline HNRNPAO & NM_006805 & heterogeneous nuclear ribonucleoprotein A0 (HNRPA0) & 3.0 \\
\hline IER2 & NM_004907 & immediate early response 2 & 2.5 \\
\hline IER3 & NM_003897 & immediate early response 3 & 9.2 \\
\hline LMNB1 & NM_005573 & Iamin B1 & 3.0 \\
\hline LRRC8B & NM_015350 & leucine rich repeat containing 8 family, member B (LRRC8B) & 2.0 \\
\hline LUZP1 & NM_033631 & leucine zipper protein 1 (LUZP1) & 2.8 \\
\hline
\end{tabular}


Table 1 List of gene set regulated by NGF in HMC-1 (V560G c-Kit) cells (Continued)

\begin{tabular}{|c|c|c|c|}
\hline MALAT1 & NR_002819 & metastasis associated lung adenocarcinoma transcript 1 (non-protein coding) & 4.9 \\
\hline MED18 & NM_017638 & mediator of RNA polymerase II transcription, subunit 18 homolog (S. cerevisiae) (MED18) & 15.0 \\
\hline METTL7A & NM_014033 & methyltransferase like $7 \mathrm{~A}$ & 2.6 \\
\hline MYEOV & NM_138768 & myeloma overexpressed (in a subset of t(11;14) positive multiple myelomas) & 3.7 \\
\hline NUP188 & BC005407 & nucleoporin 188kDa, mRNA (cDNA clone IMAGE:3461492), partial cds. [BC005407] & 2.8 \\
\hline PER2 & NM_022817 & period homolog 2 (Drosophila) & 2.5 \\
\hline PHLDA1 & NM_007350 & pleckstrin homology-like domain, family $A$, member 1 & 9.7 \\
\hline PHLDA2 & NM_003311 & pleckstrin homology-like domain, family A, member 2 & 2.3 \\
\hline PMAIP1 & NM_021127 & phorbol-12-myristate-13-acetate-induced protein 1 & 3.6 \\
\hline PRNP & NM_000311 & prion protein & 3.2 \\
\hline RAPGEF5 & D87467 & mRNA for KIAA0277 gene, partial cds. [D87467] & 18.5 \\
\hline RNF125 & NM_017831 & ring finger protein 125 & 5.1 \\
\hline RPL23 & BC034378 & ribosomal protein L23, mRNA (CDNA clone MGC:34067 IMAGE:5186030), complete cds. [BC034378] & 2.3 \\
\hline SERPINE1 & NM_000602 & serpin peptidase inhibitor, clade E (nexin, plasminogen activator inhibitor type 1), member 1 & 3.3 \\
\hline SH2B3 & NM_005475 & SH2B adaptor protein 3 & 2.4 \\
\hline $\mathrm{SH} 2 \mathrm{D} 2 \mathrm{~A}$ & NM_003975 & $\mathrm{SH} 2$ domain protein $2 \mathrm{~A}(\mathrm{SH} 2 \mathrm{D} 2 \mathrm{~A})$ & 2.1 \\
\hline SPRED1 & NM_152594 & sprouty-related, EVH1 domain containing 1 & 6.4 \\
\hline SPRED2 & NM_181784 & sprouty-related, EVH1 domain containing 2 & 3.1 \\
\hline SPRY2 & NM_005842 & sprouty homolog 2 (Drosophila) & 6.6 \\
\hline TMEM49 & NM_030938 & transmembrane protein 49 & 7.3 \\
\hline TMEPAI & NM_020182 & transmembrane, prostate androgen induced RNA (TMEPAI), transcript variant 1 & 4.2 \\
\hline TNFRSF12A & NM_016639 & tumor necrosis factor receptor superfamily, member $12 \mathrm{~A}$ & 4.8 \\
\hline UBQLN1 & NM_013438 & ubiquilin 1 & 4.6 \\
\hline ZC3H7B & NM_017590 & zinc finger $\mathrm{CCCH}$-type containing $7 \mathrm{~B}$ & 3.9 \\
\hline $\mathrm{ZCCHC2}$ & NM_017742 & zinc finger, $\mathrm{CCHC}$ domain containing 2 & 2.2 \\
\hline ZNF295 & NM_020727 & zinc finger protein 295 (ZNF295) & 2.8 \\
\hline VIL2 & NM_003379 & villin 2 (ezrin) (VIL2) & 2.3 \\
\hline
\end{tabular}

were incubated without serum for $17 \mathrm{~h}$ and were then treated with imatinib $(5 \mu \mathrm{M})$ for $4 \mathrm{~h}$. Cells were stimulated with NGF for 30 and $120 \mathrm{~min}$. All samples were standardized by expression level of glucuronidase beta (GUSB) mRNA. In agreement with the micro array data, qRT-PCR analysis revealed that immediate-early response genes, such as c-FOS (Figure 3A, 33 fold) JUNB (Figure 3B, 3-4.4 fold), and EGR1 (Figure 3C, 68-80 fold), were

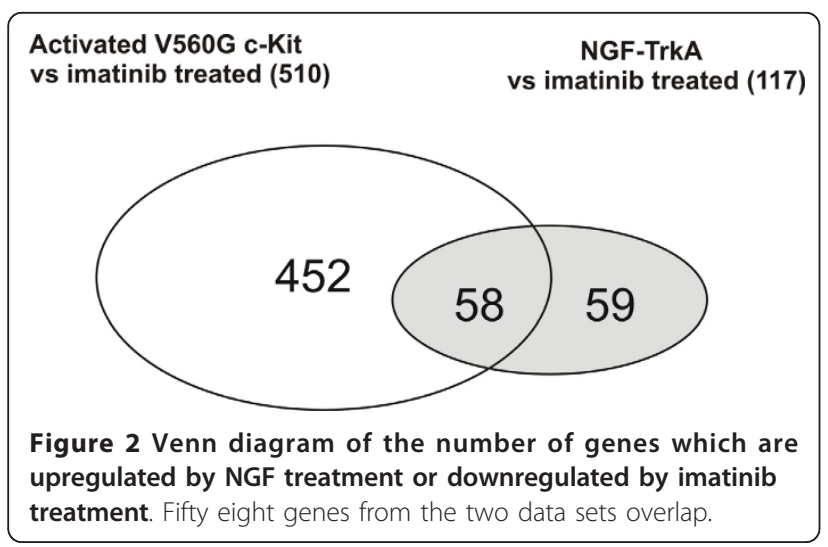

upregulated upon stimulation with NGF compared to expression level in untreated HMC-1(V560G c-Kit) cells. Standardization of RNA level using a GUSB probe was confirmed by a GAPDH probe. The relative expression level of each sample was comparable (Figure 3D). c-MYC expression was also upregulated upon stimulation with NGF in imatinib treated cells in the absence of serum, however, its expression level was lower than that in

Table 2 PANTHER analyses of c-Kit (downregulated genes by imatinib treatment) versus NGF-regulated genes which are involved in immune related function in HMC-1 (V560G c-Kit) cells (selected)

\begin{tabular}{lll}
\hline PANTHER Protein Class & $\begin{array}{l}\text { V560G c-KIT } \\
\text { (P-value) }\end{array}$ & $\begin{array}{l}\text { NGF-TrkA } \\
\text { (P-value) }\end{array}$ \\
\hline Cytokine & $2.45 E-06$ & $3.33 \mathrm{E}-03$ \\
$\begin{array}{l}\text { Cytokine/interleukin } \\
\text { superfamily }\end{array}$ & $6.74 \mathrm{E}-05$ & $2.15 \mathrm{E}-02$ \\
$\begin{array}{l}\text { Receptor } \\
\text { Receptor/cytokine receptor }\end{array}$ & $1.17 \mathrm{E}-04$ & $\mathrm{NS}$ \\
$\begin{array}{l}\text { receptor /type I cytokine } \\
\text { receptor }\end{array}$ & $3.65 \mathrm{E}-04$ & $\mathrm{NS}-03$ \\
Esterase & $2.10 \mathrm{E}-03$ & $\mathrm{NS}$ \\
\hline
\end{tabular}

NS: not significant. 
Table 3 Ingenuity biological function analyses of NGF regulated genes in HMC-1 (V560G c-Kit) cells (selected)

\begin{tabular}{|c|c|c|}
\hline $\begin{array}{l}\text { CATEGORY } \\
\text { sub category or function } \\
\text { annotation }\end{array}$ & P-value & NGF induced molecules \\
\hline \multicolumn{3}{|l|}{ 1. CELL DEATH } \\
\hline Apoptosis & $1.71 \mathrm{E}-15$ & $\begin{array}{c}\text { AATK, ADM, ATF3, CCND1, CDKN1A, CLCF1, CLN8, CXCR4, CYCS, DDIT4, DUSP4, DUSP6, EGR1, EGR2, } \\
\text { EGR3, EGR4, EZR, FASLG, FOS, FOSB, FOSL1, FST, GDF15, HES1, IER3, IL1B, KLF2, KLF10, LIF, LMNB1, LTB, } \\
\text { MCL1, MYC, NOC2L, NR4A1, NR4A2, NR4A3, PHLDA1, PHLDA2, PLK3, PMAIP1, PMEPA1, PRNP, RYBP, } \\
\text { SERPINE1, SGK1, SKIL, SLC2A3, SMAD7, SPRY2, STX1A, TNFRSF12A, TRIB1, ZFP36 }\end{array}$ \\
\hline Cell survival & 1.61E-04 & $\begin{array}{c}\text { CCND1, CDKN1A, CLCF1, DUSP5, DUSP6, EGR3, FASLG, GDF15, HES1, IL1B, LIF, MCL1, MYC, NR4A1, PRNP, } \\
\text { SERPINE1, SGK1, ZFP36 }\end{array}$ \\
\hline \multicolumn{3}{|c|}{ 2. CELL GROWTH AND PROLIFERATION } \\
\hline Growth & $4.16 \mathrm{E}-12$ & $\begin{array}{c}\text { ADM, ARNTL2, ATF3, CCND1, CDKN1A, CXCR4, DUSP5, DUSP6, EGR1, EGR2, EZR, FASLG, FOS, FOSL1, FST, } \\
\text { GDF15, GEM, GGA1, HNRNPAO, IER3, IL1B, JUNB, KLF2, KLF10, LIF, MAFF, MCL1, MYC, NR4A2, NR4A3, } \\
\text { PHLDA1, PHLDA2, PMEPA1, PRNP, RRAD, SERPINE1, SF1, SGK1, SH2B3, SKIL, SMAD7, SPRY2, TMEM49, } \\
\text { TNFRSF12A }\end{array}$ \\
\hline Proliferation & $3.46 \mathrm{E}-10$ & $\begin{array}{l}\text { ADM, CCND1, CDKN1A, CLCF1, CTSZ, CXCR4, EGR1, EGR2, EGR3, FASLG, FOS, FOSB, FOSL1, FOSL2, FST, } \\
\text { GDF15, HES1, HRH1, IER3, IL1B, JUNB, KLF2, KLF10, LIF, MYC, NAB2, NR4A1, NR4A3, PMAIP1, PRNP, } \\
\text { SERPINE1, SF1, SH2B3, SH2D2A, SKIL, SMAD7, SPRED1, SPRY2, TNFRSF12A, TRIB1, ZFP36, ZFP36L1 }\end{array}$ \\
\hline \multicolumn{3}{|l|}{ 3. CELL DEVELOPMENT } \\
\hline $\begin{array}{l}\text { Development of blood } \\
\text { cells }\end{array}$ & $1.24 \mathrm{E}-11$ & $\begin{array}{c}\text { ADM, CCND1, CDKN1A, CLCF1, CXCR4, DUSP5, EGR1, EGR2, EGR3, EZR, FASLG, FOS, FOSL1, HRH1, IER3, } \\
\text { IL1B, JUNB, KLF2, KLF10, LFNG, LIF, LTB, MYC, NR4A1, PRNP, SH2B3, SH2D2A, SMAD7, SPRED2, } \\
\text { TNFRSF12A, ZFP36 }\end{array}$ \\
\hline $\begin{array}{l}\text { Development of tumor } \\
\text { cell lines }\end{array}$ & $1.20 \mathrm{E}-10$ & $\begin{array}{l}\text { ADM, ATF3, CCND1, CDKN1A, CXCR4, DUSP5, EGR1, EGR2, FOS, FOSL1, FST, GDF15, GEM, HES1, IER3, } \\
\text { IL1B, KLF2, LIF, MCL1, MYC, NAB2, NR4A2, PMEPA1, PRNP, RRAD, SERPINE1, SMAD7, SPRY2, TMEM49 }\end{array}$ \\
\hline Differentiation of cells & 5.57E-09 & $\begin{array}{c}\text { ATF3, CCND1, CDKN1A, CLCF1, CXCR4, DUSP5, EGR1, EGR2, EGR3, FASLG, FOS, FOSL1, FOSL2, FST, HES1, } \\
\text { HRH1, IL1B, JUNB, KLF10, LIF, MAFF, MCL1, MYC, NAB2, NR4A1, NR4A2, NR4A3, PRNP, SH2B3, SKIL, } \\
\text { SMAD7, SPRED1, SPRED2, SPRY2, TNFRSF12A, ZFP36 }\end{array}$ \\
\hline Haematopoesis & $2.82 \mathrm{E}-05$ & $\begin{array}{c}\text { ATF3, CCND1, CDKN1A, CLCF1, CXCR4, DUSP5, EGR1, EGR2, EGR3, FASLG, FOS, FOSL1, FOSL2, FST, HES1, } \\
\text { HRH1, IL1B, JUNB, KLF10, LIF, MAFF, MCL1, MYC, NAB2, NR4A1, NR4A2, NR4A3, PRNP, SH2B3, SKIL, } \\
\text { SMAD7, SPRED1, SPRED2, SPRY2, TNFRSF12A, ZFP36 }\end{array}$ \\
\hline Maturation of cells & $1.73 \mathrm{E}-05$ & CCND1, CDKN1A, EGR1, FASLG, FOS, HES1, IL1B, LFNG, LIF, MYC, NR4A2, PRNP \\
\hline \multicolumn{3}{|l|}{ 4. CELL MORPHOLOGY } \\
\hline Morphology & 8.65E-10 & $\begin{array}{c}\text { ADM, ATF3, CCND1, CDKN1A, EGR1, EZR, FOS, FOSL1, GDF15, GEM, JUNB, KLF2, LIF, MYC, PLK3, } \\
\text { SERPINE1 }\end{array}$ \\
\hline Cell size & $5.16 \mathrm{E}-04$ & CCND1, CDKN1A, KLF2, MYC \\
\hline \multicolumn{3}{|c|}{ 5. CELLULAR FUNCTION AND MAINTAINANCE } \\
\hline T cell development & $2.19 \mathrm{E}-09$ & $\begin{array}{c}\text { CCND1, CDKN1A, CXCR4, EGR1, EGR2, EGR3, EZR, FASLG, FOS, IER3, IL1B, JUNB, KLF2, KLF10, LFNG, LIF, } \\
\text { LTB, MYC, NR4A1, PRNP, SH2D2A, SMAD7 }\end{array}$ \\
\hline $\begin{array}{l}\text { Cell death of T } \\
\text { lymphocytes }\end{array}$ & $8.90 \mathrm{E}-09$ & CDKN1A, CXCR4, EGR1, EGR3, EZR, FASLG, FOS, IER3, IL1B, KLF2, MYC, NR4A1, SH2D2A, SMAD7 \\
\hline \multicolumn{3}{|l|}{ 6. GENE EXPRESSION } \\
\hline Transcription & $3.62 \mathrm{E}-08$ & $\begin{array}{c}\text { ATF3, CCND1, CDKN1A, CSRNP1, DUSP4, EGR1, EGR2, EGR4, ETV5, FASLG, FOS, FOSB, FOSL1, FOSL2, FST, } \\
\text { HES1, IL1B, JUNB, KLF2, KLF10, LIF, MAFF, MYC, NAB2, NOC2L, NR4A1, NR4A2, NR4A3, PBX2, PER2, RYBP, } \\
\text { SGK1, SH2B3, SH2D2A, SKIL, SMAD7, ST18, ZFP36 }\end{array}$ \\
\hline Gene activation & 7.79E-06 & CCND1, EGR2, FOS, FOSB, FOSL1, FOSL2, KLF2, LIF, MYC, NR4A1, NR4A2 \\
\hline Gene repression & 5.37E-05 & FOS, FOSB, HES1, KLF10, MYC, NR4A2 \\
\hline
\end{tabular}

imatinib-untreated cells with serum (Figure 3E). To examine whether high c-MYC expression in untreated cells is due to the activated c-Kit kinase and/or serum which may contain activation factor(s) of the c-MYC gene, we performed c-MYC specific qRT-PCR in the presence of serum with imatinib and/or NGF (120 min). Imatinib suppressed c-MYC expression about $70 \%$ even in the presence of serum, suggesting that activated c-Kit (V560G) induces c-MYC expression. However, in the presence of serum, NGF induces c-MYC expression 2- fold more than in the absence of serum, suggesting that serum and c-Kit or TrkA tyrosine kinase synergistically induce c-MYC expression (Figure 3E).

Furthermore, 32 genes, including c-MYC, EGR1, EGR2, HES1, and KLF2 of 58 genes that were downmodulated by imatinib and upregulated upon stimulation with NGF are involved in survival and proliferation, suggesting that NGF/TrkA signaling may take over the survival and/or mitogenic signal in the imatinib treated HMC-1(V560G c-Kit) cells using these genes. 


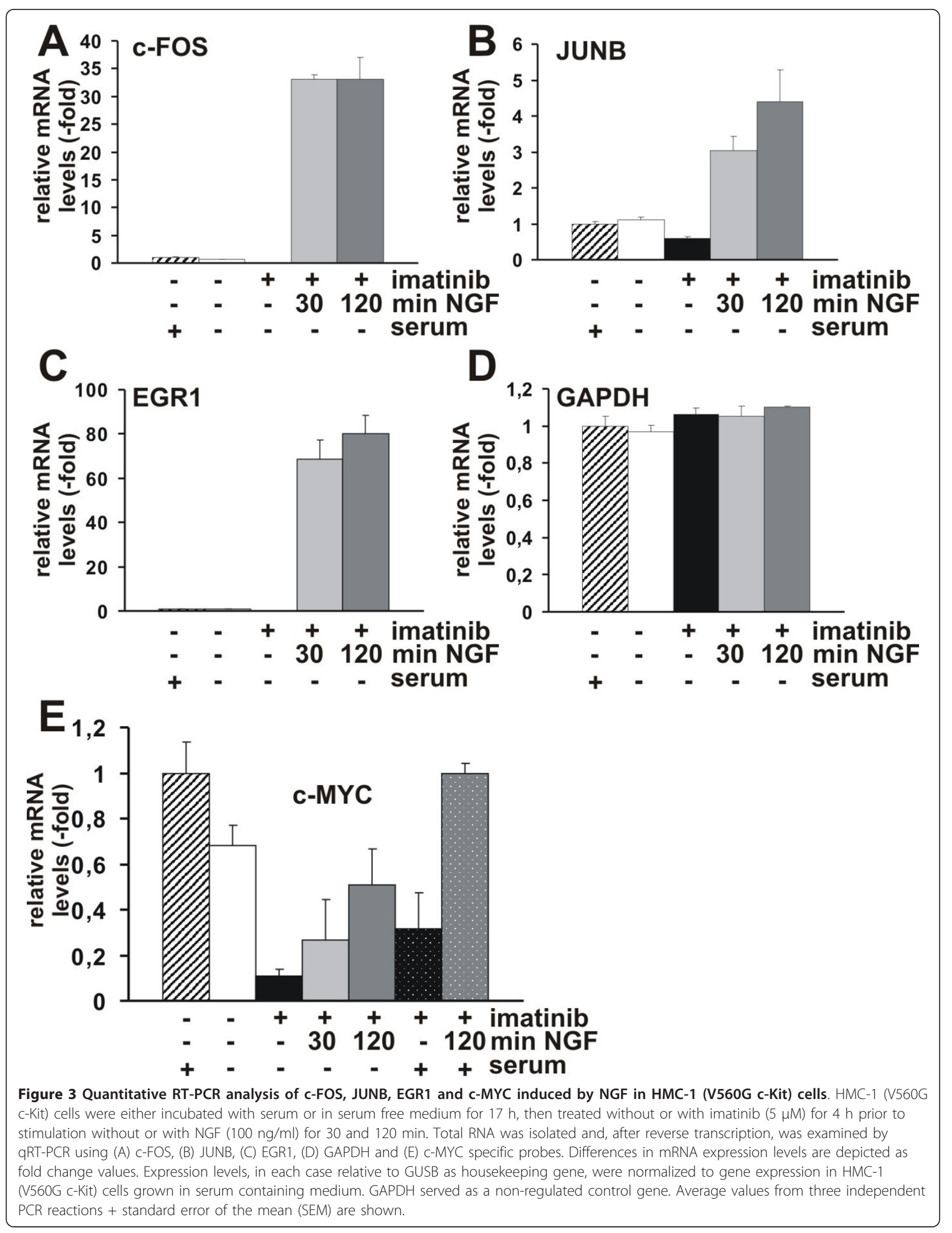


Novel target genes, KLF2, and SMAD7 which were induced by NGF-TrkA signaling are involved in anti apoptosis signal in hematopoietic cell system

Expression profiling of NGF-TrkA induced genes is well documented in neuronal cell systems [7-13]. However, there is no information about profiles of genes induced by NGF-TrkA signaling in a hematopoietic cell system. We therefore compared our upregulated genes to known NGF targets in neuronal cells. Several genes, such as the recently demonstrated ATF3, KLF10, and v-maf musculoaponeurotic fibrosarcoma oncogene family protein
F (MAFF) [7] were found to be induced in our array. In addition to the above, we show for the first time the upregulation of potential novel TrkA target genes such as KLF2, SMAD7, and Homeobox members, HOXB8 and PBX2, upon NGF stimulation in HMC-1(V560G c-Kit) cells. Since it has been shown that an immediate early gene product, KLF2 activates SMAD7 expression [24], we examined the upregulation of KLF2, SMAD7 and EGR1 by RT-PCR (Figure 4). In agreement with array data, KLF2 was upregulated within 30 min similar to the EGR1 gene, however, SMAD7 was upregulated in $2 \mathrm{~h}$ (Figure 4A),

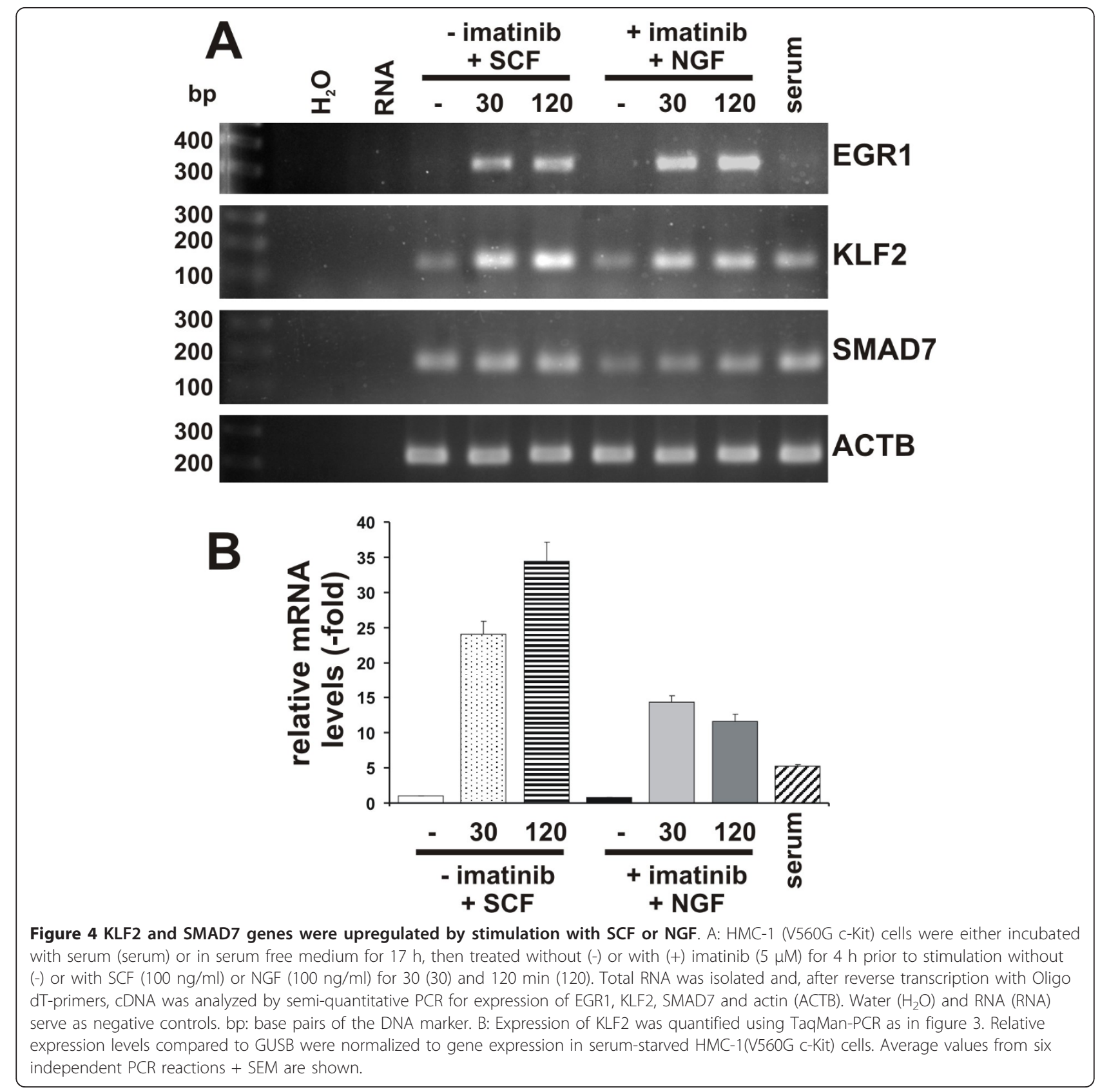


suggesting that KLF2 may be the direct target gene of NGF/TrkA signaling, but not SMAD7. We next asked whether KLF2 and SMAD7 are targets of c-Kit signaling. Since oncogenic c-Kit (V560G) is not fully activated, SCF treatment is able to induce further upregulation of c-Kit mediated signaling [25]. HMC-1(V560G c-Kit) cells were grown in the absence of serum for $17 \mathrm{~h}$, and were then stimulated with SCF (100ng/ml). The expression of KLF2, SMAD7 and EGR1 was then examined by RT-PCR. All three genes were upregulated by stimulation with SCF (Figure 4A). It should be noted that KLF2 and SMAD7 are also novel target genes for c-Kit signaling. To further confirm these data, we performed KLF2 specific qRT-PCR showing that serum starvation down-regulates KLF2 expression about 5-fold. However, upon stimulation with SCF or NGF in the absence of serum, within 30 min the KLF2 gene was upregulated 24-fold and 14-fold, respectively (Figure 4B). KLF2 is known to regulate self renewal and block the differentiation in embryo stem cells [26-28], suggesting that NGF/TrkA associates with a novel function other than neuronal differentiation. To examine whether KLF2 participates in the survival and proliferation signal induced by NGF, the KLF2 gene was downregulated by KLF2 specific siRNA in HMC-1(V560G c-Kit) cells. Two days after treatment of HMC-1 (V560G c-Kit) with KLF2 specific siRNA, the expression level of KLF2 declined to $26 \%$ (Figure 5A). The transient knockdown of KLF2 in HMC-1(V560G c-Kit) cells did not change the growth rate within 3 days after transfection under normal condition or in the presence of imatinib and NGF. We next examined whether KLF2 plays a role as a survival signal in imatinib treated HMC-1 (V560G c-Kit) cells. We began by examining caspase 3 cleavage. Cleaved caspase 3 was observed only $9 \mathrm{~h}$ after imatinib treatment in control siRNA treated cells, whereas in KLF2 specific siRNA treated cells caspase 3 was cleaved within 6 h (Figure 5B).

Furthermore, to assess the degree of apoptosis, sister culture cells were stained by an in situ cell death detection kit (Roche, Mannheim, Germany) for terminal deoxynucleotidyl transferase-mediated dUTP nick end labeling (TUNEL). In agreement with data obtained from caspase 3 cleavage, TUNEL positive cells appeared within $6 \mathrm{~h}$ after imatinib treatment in both KLF2 specific siRNA and control siRNA treated cells. However, numbers of TUNEL positive cells increased significantly faster in KLF2 siRNA treated cells than in control siRNA transfected cells $6(\mathrm{p}=0.008), 9(\mathrm{p}=0.009)$ and $15 \mathrm{~h}(\mathrm{p}=0.0005)$ after imatinib treatment (Figure $5 \mathrm{C})$.

Since KLF2 specific siRNA transfectants still grow in the presence of NGF and imatinib, additional survival signals may be mediated by NGF treatment. However, our data strongly suggest that KLF2 is involved in an anti-apoptosis signal.

\section{Discussion}

Cell differentiation and self-renewal are paralleled by a timely, ordered expression of a set of cytokines, growth factors and corresponding receptors. Many members of receptor tyrosine kinase family have emerged as key regulators of these critical cellular processes $[4,29,30]$. Humans have 58 known receptor tyrosine kinases, which fall into 20 subfamilies. Despite differences in structure, many of tyrosine kinases signal through the same pathways to typically enhance proliferation and prolong viability. These pathways include activation of the Ras/Raf/Erk, STATs and PI3K. These facts raised the question of whether each receptor tyrosine kinase is associated with a similar signaling potential, regulated by different expression patterns in different cell types, or whether each tyrosine kinase exhibits a unique signaling pathway.

It has previously been shown that TrkA and c-Kit are co-expressed in mast cells and hematopoietic CD34 positive cells. The treatment of CD34 positive cells with NGF showed the synergistic effects with the SCF treatment on colony formation. For mast cell culture in vitro, bone marrow cells are cultivated for 4-6 weeks in the presence of SCF, interleukin (IL) 3 and IL4 [31]. We examined whether mouse primary mast cells can survive in the presence of NGF, or NGF and IL3/IL4 in the absence of SCF. Under these conditions mouse mast cells did not survive in the absence of SCF. These data suggest that NGF does not assume the role of SCF in normal mast cells. According to PANTHER analysis $[32,33]$, the difference of gene upregulation of cytokines, growth factors, and their receptors between SCF and NGF stimulation is significant, suggesting that upregulation of cytokines and their receptors play a role in survival of normal mast cells. In agreement with these data, few genes encoding cytokines/their receptors in PC12 cells were upregulated $24 \mathrm{~h}$ after NGF treatment [9], suggesting that NGF poorly induces cytokine and growth factor genes in different cell types.

It has been shown that STAT5 is required for c-Kit mediated mast cell survival and differentiation [23]. Although NGF does not induce tyrosine phosphorylation of STATs, HMC-1(V560G c-Kit) cells survive by NGF stimulation without c-Kit signaling. Thereby our array data provide novel candidate genes, KLF2, SMAD7, PBX2, and HOXB8 which are induced by NGF/TrkA activation in hematopoietic cells, and have not been reported as NGF target genes in the PC12 cell system [7-14]. On the other hand, another known target gene of NGF treatment in PC12 cells, wingless-related MMTV integration site 7B (Wnt7b) [14] was not upregulated by NGF treatment in HMC-1 (V560G c-Kit) cells, suggesting that Wnt7b may be a specific target gene for NGF signaling in neuronal 


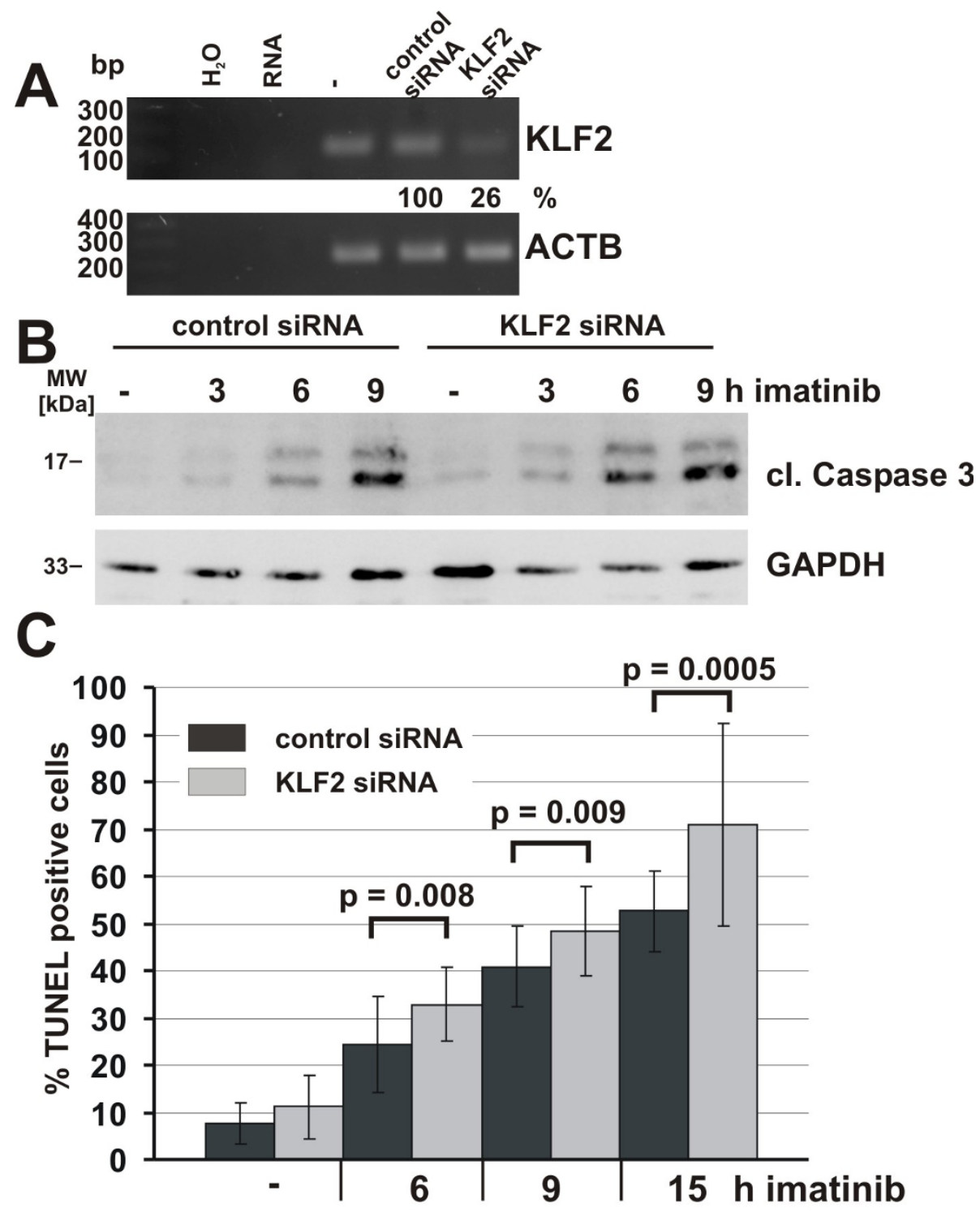

Figure 5 Knockdown of KLF2 modulates the imatinib induced apoptosis. A: HMC-1 cells were transfected with control siRNA or siRNA directed against KLF2 (KLF2 siRNA). $48 \mathrm{~h}$ after transfection, CDNA of untransfected (-) and transfected cells (control siRNA and KLF2 siRNA) was prepared and analyzed for expression of KLF2 and actin (ACTB) by semi-quantitative RT-PCR. KLF2 bands were quantified using TINA2.0 software and were normalized to actin. B: SiRNA transfected cells as in A were treated with imatinib $(5 \mu \mathrm{M})$ for the indicated times. Every $3 \mathrm{~h}$, whole cell lysates were prepared for detection of cleaved caspase-3 (cl. Caspase 3) and GAPDH by immunoblot. C: Cells were transfected and treated with imatinib as in B. At the indicated times after imatinib treatment, cells were fixed with paraformaldehyde and apoptotic cells were detected by TUNEL staining. Observations from different fields in the microscope (between 300 and 700 cells per experimental condition) are depicted as the mean +/- SD of \% TUNEL positive cells. Student's t-test was applied to describe the significance of differences between cells treated with control siRNA and KLF2 siRNA. P-values $\leq 0.05$ were considered as significant and are indicated above the corresponding columns. bp: base pairs of the DNA marker. MW: molecular weight.

cells. These data indicate that most NGF upregulated genes were common, but some of them may be cell-type specific. However, we cannot presently rule out the possibility that the difference of upregulated genes is due to differences between human (HMC-1) and rat (PC12) cells. Interestingly, KLF2, SMAD7, PBX2, and HOXB8 are suggested to be involved in self-renewal or in anti differentiation signal of stem cells or hematopoietic stem cells [26,34-37]. We show here that KLF2 modulates imatinib-mediate apoptosis. Along the same line, it has been shown that KLF2-deficient $\mathrm{T}$ cells had a spontaneously activated phenotype and died rapidly from Fas-ligand-induced apoptosis [38], and induction of KLF2 expression corresponded with long-term $\mathrm{T}$ cell 
survival [39], suggesting that KLF2 plays a role in T cell survival. Furthermore, KLF2-/- embryos have a significantly increased number of primitive erythroid cells undergoing apoptotic cell death. These data suggest that the upregulation of the KLF2 gene induced by the stimulation with NGF plays a role in the survival signal in imatinib treated HMC-1(V560G c-Kit) cells.

\section{Conclusion}

We compared the signaling of two structurally and functionally diverse receptor tyrosine kinases, c-Kit and TrkA, in hematopoietic cells. The c-Kit activation induces cytokines and their receptors, but TrkA does not, suggesting that the part of the signal pathways induced by the two receptors is different. However, TrkA is able to induce common novel downstream targets such as KLF2 and SMAD7 which has not been reported in the neuronal system, indicating that NGF induces genes which are involved in stem cell maintenance similar to c-Kit signaling in hematopoietic cells. Furthermore, upregulation of KLF2 may be involved in NGF mediated survival of imatinib treated cells.

\section{Methods}

\section{Cell lines}

HMC-1(V560G c-Kit) [16] were grown in RPMI1640 medium supplemented with 10-20\% (v/v) fetal calf serum (FCS). The presence of V560G mutation and the absence of 816 mutation in c-Kit was confirmed by sequencing.

\section{Viability assay}

HMC-1(V560G c-Kit) cells were grown in medium containing $10 \%$ FCS in the presence of $5 \mu \mathrm{M}$ imatinib (kindly provided by Novartis, Basel, Switzerland) and/or $100 \mathrm{ng} / \mathrm{ml}$ human recombinant NGF (PeproTech Inc., Rocky Hill, NJ). Cells were counted in a Neubauer chamber using 0.1\% Trypan Blue (Sigma-Aldrich Chemie $\mathrm{GmbH}$, Steinheim, Germany).

\section{TUNEL assay}

To assess the degree of apoptosis, an in situ cell death detection kit (Roche, Mannheim, Germany) was used for terminal deoxynucleotidyl transferase-mediated dUTP nick end labeling (TUNEL) staining.

\section{Growth factor stimulation, and RNA-isolation}

Cells were serum starved for $17 \mathrm{~h}$, then treated with dimethyl sulfoxide (DMSO) or $5 \mu \mathrm{M}$ imatinib for 4 hours prior to stimulation with $100 \mathrm{ng} / \mathrm{ml}$ mouse recombinant SCF (PeproTech Inc.) or NGF, respectively. After 30 or 120 min the stimulation was stopped in ice-cold PBS. RNA was isolated from growth factor treated or untreated HMC-1(V560G c-Kit) cells using RNeasy Mini kit (Qiagen, Hilden, Germany) according to the manufacturer's protocol. Residual DNA contamination was removed with DNAseI (Invitrogen $\mathrm{GmbH}$, Darmstadt, Germany) according to the manufacturer's recommendations, and the RNA was again purified with RNeasy Mini kit (Qiagen).

\section{Microarray analysis}

The "Whole Human Genome Microarray" (G4112F, ID 014850, Agilent Technologies) used in this study contained 45015 oligonucleotide probes covering the entire human transcriptome. cRNA-synthesis was performed with the "Low RNA Input Linear Amplification Kit PLUS, Two-Color" (\#5188-5340, Agilent Technologies) as directed by the manufacturer. cRNA fragmentation, hybridization and washing steps were also performed exactly as recommended by the manufacturer "Two-Color Microarray-Based Gene Expression Analysis Protocol V5.5” (see http://www.agilent.com for details) except that $4 \mu \mathrm{g}$ of each labeled cRNA were used for hybridization. Slides were scanned on the Agilent Micro Array Scanner G2505 B at two different PMT settings, namely 100\% (default setting) and 5\%, to increase the dynamic range of the measurements. Data extraction and normalization were performed with the "Feature Extraction Software V9.5.3.1" by using the recommended default extraction protocol file: GE2-v5_95_Feb07.xml. Only probes with allocated gene symbols and arithmetic mean intensity $>50$ for both channels were considered for further analysis. Genes with $p$ value $\leq 0.0001$ and fold induction ratio of $\geq 2$ were considered significantly induced.

\section{Accession Numbers}

The complete microarray data have been deposited in NCBI's Gene Expression Omnibus and are accessible through GEO series accession number GSE28045.

\section{Functional and gene ontology analysis}

Categorization of genes according to protein class was done using PANTHER (Protein Analysis Through Evolutionary Relationships) Classification Systems [32]. For each protein class, PANTHER calculates the number of genes identified in that category in both the list of differentially regulated genes and a reference list containing all the probe sets present on the chip and compares these results using the binomial test to determine if there are more genes than expected in the differentially regulated list [33]. Over-representation is defined by $\mathrm{p}<$ 0.05. Functional Analysis identifying the biological functions that were most significant to the data set were carried out using Ingenuity Pathways Analysis (IPA) (Ingenuity Systems, Mountain View, CA). Right-tailed Fisher's exact test was used to calculate a p-value determining the probability that each biological function and/ 
or disease assigned to that data set is due to chance alone.

\section{RT-PCR and qRT-PCR}

Reverse transcription was carried out using oligo dT primers and the Omniscript reverse transcriptase kit (Qiagen) following the instructions provided. PCRs were set up according to the following profile: an initial denaturation step of $94^{\circ} \mathrm{C}$ for $2 \mathrm{~min}$, repeating cycles of $94^{\circ} \mathrm{C}$ for $30 \mathrm{sec}-$ onds, annealing temperature given for each primer pair for 1 minute, and $72^{\circ} \mathrm{C}$ for 1 minute. Following primer pairs were used: human EGR-1 (NM_001964) forward primer: 5'-CAGCAGTCCCATTTACTCAG-3', reverse primer: 5'GACTGGTAGCTGGTATTG-3' (annealing temperature $56^{\circ} \mathrm{C}$, product size $345 \mathrm{bp}$ ); human KLF2 (NM_016270) forward primer: 5'-CTACACCAAGAGTTCGCATCTG3', reverse primer: 5'-CCGTGTGCTTTCGGTAGTG$3^{\prime}$ (annealing temperature $57^{\circ} \mathrm{C}$, product size $137 \mathrm{bp}$ ); human SMAD7 (NM_005904) forward primer: 5'-ACTCCAGATACCCGATGGATTT-3', reverse primer: 5'CCTCCCAGTATGCCACCAC-3' (annealing temperature $57^{\circ} \mathrm{C}$, product size $174 \mathrm{bp}$ ); human beta-actin (ACTB, NM_001101) forward primer: 5'-CCCAAGGCCAAC CGCGAGAAGAT-3', reverse primer: 5'-GTCCCGGCC AGCCAGGTCCAG-3' (annealing temperature $66^{\circ} \mathrm{C}$, product size $219 \mathrm{bp}$ ). Separation of the DNA fragments was carried out on $2 \%(\mathrm{w} / \mathrm{v})$ agarose gels, stained with ethidium bromide $(2 \mu \mathrm{g} / \mathrm{ml})$ and photographed under UV light. Quantitative (TaqMan) RT-PCR was performed as previously described [40]. TaqMan probes (Applied Biosystems, assay-IDs as follows: Hs00152928_m1(EGR1); Hs00357891_s1(JUNB); Hs00170630_m1(FOS); Hs001 53408_m1(MYC); Hs00360439_g1(KLF2); Hs99999 905_m1(GAPDH); Hs99999908_m1(GUSB)) were used with TaqMan ${ }^{\circledR}$ Fast Universal PCR Master Mix $(2 \times)$ (Applied Biosystems).

\section{Transfection, RNA interference and immunoblotting}

SiRNA against human LKLF (KLF2) and control siRNA was purchased from Santa Cruz Biotechnology (Santa Cruz, CA). $4 \times 10^{6}$ HMC-1(V560G c-Kit) cells were transfected with 200 pmol of siRNA using Amaxa ${ }^{\circledR}$ Cell Line Nucleofector Kit L with program T-020 in an Amaxa ${ }^{\circledR}$ Nucleofector ${ }^{\circledR}$ II device according to the manufacturer's instructions. Two days after transfection, cells were treated with imatinib $(5 \mu \mathrm{M})$ for up to $15 \mathrm{~h}$. During imatinib treatment, aliquots were prepared for analysis by TUNEL staining or immunoblot.

For immunoblot analysis, whole cell lysates were prepared using $1 \times$ SDS buffer $(80 \mathrm{mM}$ Tris/HCl, pH 6.8, $2 \%$ sodium dodecyl sulfate (SDS), $10 \%$ glycerol, $5 \%$ betamercaptoethanol, $0.01 \%$ bromphenole blue). Then, cell lysates were analyzed for cleavage fragments of caspase 3 by immunoblot analysis using a polyclonal antibody against cleaved caspase-3 (Asp175) (Cell Signaling Technology, Beverly, MA) or GAPDH (Santa Cruz Biotechnology) as described previously [15]. Knockdown of KLF2 was verified by semi-quantitative RT-PCR and quantitative analysis was performed using TINA2.0 software (Raytest Isotopenmessgeraete $\mathrm{GmbH}$, Straubenhardt, Germany).

\section{Acknowledgements}

We thank Sabine Klebba-Färber for technical assistance and Bruce Boschek for critically reading the manuscript. P.D. was supported by the MD PhD program of the Medizinische Hochschule Hannover (MHH), A. K. was supported by the Madeleine Schickedanz-Kinderkrebsstiftung, WiedekingStiftung, Habilitationsstipendium (MHH) and the HiLF program (MHH). The research was supported by Sonderforschungsbereich 566 (B2, Z2), and by the Leistungsorientierte Mittelvergabe (LOM) of MHH with Frauen-Faktor. The publication of this article was funded by the program "Open Access Publizieren" of Deutsche Forschungsgemeinschaft.

\section{Author details}

${ }^{1}$ Institut fuer Biochemie, OE4310, Medizinische Hochschule Hannover, Carl-Neuberg-Str. 1, D-30623 Hannover, Germany. ${ }^{2}$ Institut fuer Pharmakologie, Justus-Liebig-Universität Giessen, Frankfurt Str. 107, D-35392, Giessen, Germany.

\section{Authors' contributions}

PD isolated RNA, carried out cell culture, and analyzed microarray data. AK carried out cell culture, immunoblot, siRNA and RT-PCR. BB analyzed microarray data by IPA HS, and ODB generated the microarray and the qRT$P C R$ data, MK provided the microarray facility, $\Pi$ participated in the design of the study, contributed to the data analysis, and wrote and finalized manuscript. All authors participated in the discussion and approved the final manuscript.

Received: 7 December 2010 Accepted: 18 April 2011

Published: 18 April 2011

\section{References}

1. Kaplan DR, Miller FD: Neurotrophin signal transduction in the nervous system. Curr Opin Neurobiol 2000, 10(3):381-391.

2. Auffray I, Chevalier S, Froger J, Izac B, Vainchenker W, Gascan H, Coulombel L: Nerve growth factor is involved in the supportive effect by bone marrow-derived stromal cells of the factor-dependent human cell line UT-7. Blood 1996, 88(5):1608-1618.

3. Chevalier S, Praloran V, Smith C, MacGrogan D, Ip NY, Yancopoulos GD, Brachet P, Pouplard A, Gascan H: Expression and functionality of the trkA proto-oncogene product/NGF receptor in undifferentiated hematopoietic cells. Blood 1994, 83(6):1479-1485.

4. Lemmon MA, Schlessinger J: Cell signaling by receptor tyrosine kinases. Cell 2010, 141(7):1117-1134.

5. Meyer J, Rhein M, Schiedlmeier B, Kustikova O, Rudolph C, Kamino K, Neumann T, Yang M, Wahlers A, Fehse B, et al: Remarkable leukemogenic potency and quality of a constitutively active neurotrophin receptor, deltaTrkA. Leukemia 2007, 21(10):2171-2180

6. Ng YP, Cheung ZH, Ip NY: STAT3 as a downstream mediator of Trk signaling and functions. The Journal of biological chemistry 2006, 281(23):15636-15644.

7. Dijkmans TF, van Hooijdonk LW, Schouten TG, Kamphorst JT, Fitzsimons CP, Vreugdenhil E: Identification of new Nerve Growth Factor-responsive immediate-early genes. Brain research 2009, 1249:19-33.

8. Dijkmans TF, van Hooijdonk LW, Schouten TG, Kamphorst JT, Vellinga AC, Meerman JH, Fitzsimons CP, de Kloet ER, Vreugdenhil E: Temporal and functional dynamics of the transcriptome during nerve growth factorinduced differentiation. Journal of neurochemistry 2008, 105(6):2388-2403.

9. Kunz D, Walker G, Bedoucha M, Certa U, Marz-Weiss P, DimitriadesSchmutz B, Otten U: Expression profiling and Ingenuity biological function analyses of interleukin-6- versus nerve growth factor-stimulated PC12 cells. BMC genomics 2009, 10:90. 
10. Lee $\mathrm{KH}$, Ryu CJ, Hong HJ, Kim J, Lee EH: CDNA microarray analysis of nerve growth factor-regulated gene expression profile in rat PC12 cells. Neurochemical research 2005, 30(4):533-540.

11. Lee NH, Weinstock KG, Kirkness EF, Earle-Hughes JA, Fuldner RA Marmaros S, Glodek A, Gocayne JD, Adams MD, Kerlavage A, et al: Comparative expressed-sequence-tag analysis of differential gene expression profiles in PC-12 cells before and after nerve growth factor treatment. Proceedings of the National Academy of Sciences of the United States of America 1995, 92(18):8303-8307.

12. Mayumi K, Yaoi T, Kawai J, Kojima S, Watanabe S, Suzuki H: Improved restriction landmark cDNA scanning and its application to global analysis of genes regulated by nerve growth factor in PC12 cells. Biochimica et biophysica acta 1998, 1399(1):10-18.

13. Marek L, Levresse V, Amura C, Zentrich E, Van Putten V, Nemenoff RA Heasley LE: Multiple signaling conduits regulate global differentiationspecific gene expression in PC12 cells. Journal of cellular physiology 2004 201(3):459-469.

14. Brynczka C, Merrick BA: The p53 transcriptional target gene wnt7b contributes to NGF-inducible neurite outgrowth in neuronal PC12 cells. Differentiation; research in biological diversity 2008, 76(7):795-808.

15. Koch A, Scherr M, Breyer B, Mancini A, Kardinal C, Battmer K, Eder M, Tamura T: Inhibition of Abl tyrosine kinase enhances nerve growth factor-mediated signaling in Bcr-Abl transformed cells via the alteration of signaling complex and the receptor turnover. Oncogene 2008, 27(34):4678-4689.

16. Butterfield JH, Weiler D, Dewald G, Gleich GJ: Establishment of an immature mast cell line from a patient with mast cell leukemia. Leuk Res 1988, 12(4):345-355.

17. Furitsu $T$, Tsujimura $T$, Tono $T$, Ikeda $H$, Kitayama $H$, Koshimizu $U$, Sugahara $H$, Butterfield JH, Ashman LK, Kanayama $Y$, et al: Identification of mutations in the coding sequence of the proto-oncogene c-kit in a human mast cell leukemia cell line causing ligand-independent activation of c-kit product. J Clin Invest 1993, 92(4):1736-1744.

18. Kitayama $H$, Kanakura $Y$, Furitsu T, Tsujimura T, Oritani $K$, Ikeda $H$, Sugahara H, Mitsui H, Kanayama $Y$, Kitamura $Y$, et al: Constitutively activating mutations of c-kit receptor tyrosine kinase confer factorindependent growth and tumorigenicity of factor-dependent hematopoietic cell lines. Blood 1995, 85(3):790-798.

19. Tam SY, Tsai M, Yamaguchi M, Yano K, Butterfield JH, Galli SJ: Expression of functional TrkA receptor tyrosine kinase in the HMC-1 human mast cell line and in human mast cells. Blood 1997, 90(5):1807-1820.

20. Welker P, Grabbe J, Grutzkau A, Henz BM: Effects of nerve growth factor (NGF) and other fibroblast-derived growth factors on immature human mast cells (HMC-1). Immunology 1998, 94(3):310-317.

21. Frost MJ, Ferrao PT, Hughes TP, Ashman LK: Juxtamembrane mutant V560GKit is more sensitive to Imatinib (STI571) compared with wild-type c-kit whereas the kinase domain mutant D816VKit is resistant. Mol Cancer Ther 2002, 1(12):1115-1124.

22. Heinrich MC, Griffith DJ, Druker BJ, Wait CL, Ott KA, Zigler AJ: Inhibition of c-kit receptor tyrosine kinase activity by STI 571, a selective tyrosine kinase inhibitor. Blood 2000, 96(3):925-932.

23. Shelburne CP, McCoy ME, Piekorz R, SexI V, Roh KH, Jacobs-Helber SM, Gillespie SR, Bailey DP, Mirmonsef P, Mann MN, et al: Stat5 expression is critical for mast cell development and survival. Blood 2003, 102(4):1290-1297.

24. Boon RA, Fledderus JO, Volger OL, van Wanrooij EJ, Pardali E, Weesie F, Kuiper J, Pannekoek H, ten Dijke P, Horrevoets AJ: KLF2 suppresses TGFbeta signaling in endothelium through induction of Smad7 and inhibition of AP-1. Arteriosclerosis, thrombosis, and vascular biology 2007 27(3):532-539.

25. Roskoski R Jr: Structure and regulation of Kit protein-tyrosine kinase-the stem cell factor receptor. Biochemical and biophysical research communications 2005, 338(3):1307-1315.

26. Jiang J, Chan YS, Loh YH, Cai J, Tong GQ, Lim CA, Robson P, Zhong S, $\mathrm{Ng} \mathrm{HH}$ : A core Klf circuitry regulates self-renewal of embryonic stem cells. Nature cell biology 2008, 10(3):353-360.

27. Blank U, Karlsson G, Moody UL, Utsugisawa T, Magnusson M, Singbrant S, Larsson J, Karlsson S: Smad7 promotes self-renewal of hematopoietic stem cells. Blood 2006, 108(13):4246-4254.

28. Hall J, Guo G, Wray J, Eyres I, Nichols J, Grotewold L, Morfopoulou S, Humphreys P, Mansfield W, Walker R, et al: Oct4 and LIF/Stat3 additively induce Kruppel factors to sustain embryonic stem cell self-renewal. Cell stem cell 2009, 5(6):597-609.

29. Blume-Jensen P, Hunter T: Oncogenic kinase signalling. Nature 2001, 411(6835):355-365

30. Ullrich A, Schlessinger J: Signal transduction by receptors with tyrosine kinase activity. Cell 1990, 61(2):203-212.

31. Tsuji K, Zsebo KM, Ogawa M: Murine mast cell colony formation supported by IL-3, IL-4, and recombinant rat stem cell factor, ligand for c-kit. Journal of cellular physiology 1991, 148(3):362-369.

32. Thomas PD, Campbell MJ, Kejariwal A, Mi H, Karlak B, Daverman R, Diemer K, Muruganujan A, Narechania A: PANTHER: a library of protein families and subfamilies indexed by function. Genome research 2003 13(9):2129-2141

33. Thomas PD, Kejariwal A, Guo N, Mi H, Campbell MJ, Muruganujan A Lazareva-Ulitsky B: Applications for protein sequence-function evolution data: $\mathrm{mRNA}$ /protein expression analysis and coding SNP scoring tools. Nucleic acids research 2006, , 34 Web Server: W645-650.

34. Argiropoulos B, Humphries RK: Hox genes in hematopoiesis and leukemogenesis. Oncogene 2007, 26(47):6766-6776.

35. Bourillot PY, Aksoy I, Schreiber V, Wianny F, Schulz H, Hummel O, Hubner $N_{\text {, }}$ Savatier P: Novel STAT3 target genes exert distinct roles in the inhibition of mesoderm and endoderm differentiation in cooperation with Nanog. Stem cells (Dayton, Ohio) 2009, 27(8):1760-1771.

36. Perkins $A C$, Cory S: Conditional immortalization of mouse myelomonocytic, megakaryocytic and mast cell progenitors by the Hox2.4 homeobox gene. The EMBO journal 1993, 12(10):3835-3846

37. Wong $\mathrm{P}$, Iwasaki M, Somervaille TC, So CW, Cleary ML: Meis1 is an essentia and rate-limiting regulator of MLL leukemia stem cell potential. Genes \& development 2007, 21(21):2762-2774.

38. Kuo CT, Veselits ML, Leiden JM: LKLF: A transcriptional regulator of singlepositive T cell quiescence and survival. Science (New York, NY) 1997, 277(5334):1986-1990.

39. Schober SL, Kuo CT, Schluns KS, Lefrancois L, Leiden JM, Jameson SC: Expression of the transcription factor lung Kruppel-like factor is regulated by cytokines and correlates with survival of memory T cells in vitro and in vivo. J Immunol 1999, 163(7):3662-3667.

40. Dhamija S, Doerrie A, Winzen R, Dittrich-Breiholz O, Taghipour A, Kuehne N, Kracht M, Holtmann H: IL-1-induced post-transcriptional mechanisms target overlapping translational silencing and destabilizing elements in IkappaBzeta mRNA. The Journal of biological chemistry 2010,

285(38):29165-29178

doi:10.1186/1471-2164-12-196

Cite this article as: Dutta et al:: Identification of novel target genes of nerve growth factor (NGF) in human mastocytoma cell line (HMC-1 (V560G c-Kit)) by transcriptome analysis. BMC Genomics 2011 12:196.

\section{Submit your next manuscript to BioMed Central and take full advantage of:}

- Convenient online submission

- Thorough peer review

- No space constraints or color figure charges

- Immediate publication on acceptance

- Inclusion in PubMed, CAS, Scopus and Google Scholar

- Research which is freely available for redistribution

Submit your manuscript at www.biomedcentral com/submit
C Biomed Central 